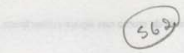

\title{
ANOMALIA DE CROMO NAS ȦGUAS SUBTERRÂNEAS DE URÂNIA NO NOROESTE DO ESTADO DE SÃO PAULO ${ }^{1}$
}

\author{
M.L.N.Almodovar ${ }^{2} \&$ A.Pacheco ${ }^{3}$
}

PALAVRAS-CHAVE: cromo, águas subterrâneas, anomalia, geoquímica, saúde pública.

ALMODOVAR, M.L.N.; PACHECO, A. (1995) Anomalia de cromo nas águas subterrâneas de Urânia no noroeste do Estado de São Paulo. Bol.IG-USP, Sér.Cient., 26:1-12.

\section{RESUMO}

A ocorrência de cromo nas águas subterrâneas da região noroeste do Estado de São Paulo tem-se configurado como uma grande preocupaçăo, uma vez que as cidades possuem no recurso hidrico subterrảneo a única fonte de água para suprir suas necessidades. Esta pesquisa objetivou caracterizar a extensão da anomalia de cromo nas águas subterrâneas daquela regiăo; desenvolver um estudo geoquímico das águas, sedimentos e rochas da cidade de Urânia; definir a relação saúde pública e a presença de cromo nas águas subterrâneas utilizadas para abastecimento público. Através das análises quimicas de águas subterrâneas em localidades do noroeste paulista, feitas no período de 1977 a 1993. pela Companhia Estadual de Saneamento Básico (SABESP), sabe-se que esta anomalia estende-se a outros municípios da regiâo noroeste do Estado. Estudos geoquimicos dos sedimentos da Formação Adamantina e rochas basálticas da Formação Serra Geral da cidade de Urånia mostraram que, enquanto as concentraçôes de cromo nos primeiros estão acima da média encontrada em sedimentos similares da crosta terrestre, nas rochas basálticas, as concentrações estảo abaixo da média dos basaltos da crosta. Um levantamento sobre a saúde da população de Urânia, mostrou que não foi realizado nenhum estudo na regiâo que comprovasse doenças causadas pela ingestão de água contendo cromo acima do limite de potabilidade. Através da integração dos dados e do estudo sistemático dos teores de cromo nas águas, sedimentos e rochas, chegou-se às seguintes conclusôes; a anomalia de cromo estende-se alèm da cidade de Uránia, a outros municipios e distritos do noroeste paulista; a distribuicäo das concentraçōes de cromo é irregular, tanto temporal quanto espacialmente; a origem do cromo é discutivel, apesar de fortes evidências de ser natural, são necessários estudos mais aprofundados; não se têm conclusôes evidentes, se a anomalia de cromo causa problemas à saúde da populaçāo abastecida por estas águas.

\section{ABSTRACT}

The existence of chromium in groundwater is a subject of great concern in the northwestern region of the State of Sâo Paulo, where cities depend on groundwater resources for their only source of water. This paper attempts to characterize the areal extent of the chromium anomaly in groundwater in this region; to develop a geochemical study of water, sediments and rocks in the city of Uränia; and to define the relation between public health and the presence of chromium in groundwater for

\footnotetext{
'Trabalho financiado pela FAPESP através do processo 94/1995-3

${ }^{2}$ Aluna Pós-Graduanda, IGIUSP.

${ }^{3}$ Centro de Pesquisas de Águas Subterrâneas, Departamento de Geologia Econôrnica e Geofisica Aplicada, Instituto de Geociências/USP, São Paulo, Brasil.
} 
public consumption. Through the combination of data and the systematic study of chromium levels in water, sediments and rocks, the following conclusions were drawn: the chromium anomaly is not only present in the city of Urânia, but also in other municipalities and districts in northwest São Paulo; the distribution of chromium concentrations is irregular, both in time and space; the source of the chromium is subject to discussion, despite strong evidence that it is natural. However, more in-depth studies are necessary; no relevant conclusions can be drawn about the problems caused by the chromium anomaly to the health of the population served by this water.

\section{INTRODUĈ̣̃O}

A presença da anomalia de cromo nas águas subterrâneas da região noroeste do Estado de São Paulo tem sido verificada desde 1977. Inicialmente, foi constatada em águas provenientes de poços profundos e cacimbas no município de Urânia, região de Jales. Posteriormente, detectou-se que esta anomalia estendia-se a outros municípios do noroeste paulista.

As concentrações de cromo são variáveis em cada município e em alguns locais ultrapassam os limites máximos permitidos em águas para o consumo humano, cujo valor é $0,05 \mathrm{mg} / \mathrm{l}$. Este valor está de acordo com o Decreto Estadual 12.486 de 20-10-78 e com a Portaria 36, do Ministério da Saúde, de 19-01-90 (CETESB, 1994).

Como a presença deste elemento afeta a qualidade das águas subterrâneas, recurso de grande importância social, econômica e estratégica, foi necessário um estudo mais abrangente da região, a fim de averiguar a ocorrência da anomalia de cromo nestas águas, para que fosse possivel buscar formas de amenizaçāo do problema.

A pesquisa objetivou caracterizar a extensâo da anomalia de cromo nas águas subterrâneas da região noroeste do Estado de Sāo Paulo; desenvolver um estudo geoquímico das águas, sedimentos e rochas da cidade de UrâniaSP; definir a relação entre a saúde pública e a presença de cromo nas águas subterrâneas utilizadas para abastecimento público.

Este trabalho é o extrato da Dissertação de Mestrado Estudo da anoma- lia de cromo das águas subterrâneas da região noroesie do Estado de São Paulo (Almodovar, 1995).

\section{HIDROGEOLOGIA DA ÁREA}

A área onde foi desenvolvida a pesquisa está localizada na região noroeste do Estado de São Paulo. Foi selecionado o município de Urânia para estudo de detalhe (Fig. 1). Nesta região afloram os sedimentos da Formação Adamantina, do Grupo Bauru. Estes sedimentos encontram-se sobre os basaltos da Formação Serra Geral, conforme atestam os poços tubulares da região.

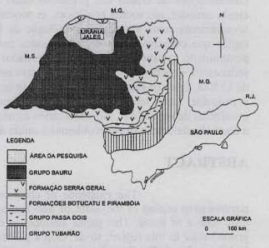

Figura 1 - Esboço geológico da Bacia do Paraná e localização geográfica da pesquisa. Fonte: IPT, 1981 (adaptado).

A Formação Adamantina é constituída por bancos de arenitos alternados com lamitos, siltitos e arenitos lamíticos (Soares et al., 1980). Coimbra (1976) 
indica como área fonte os sedimentos fanerozóicos pré-existentes a noroeste e sudeste, áreas de rochas básicas do Grupo São Bento, metamórficas dos Grupos Araxá e Canastra e alcalinas do Triângulo Mineiro a nordeste. Brandt Neto (1977), estudando a Formação Adamantina na região de Araçatuba e Penápolis, no Baixo Tietê, observou em trinta e oito amostras que a ocorrência de minerais pesados se concentrou em turmalina e estaurolita, predominantemente, e granada, zircão, rutilo e perowskita, secundariamente. Os argilo-minerais reconhecidos por Brandt Neto (1984) e Brandt Neto et al. (1985) são a caulinita, montimorillonita e paligosrquita.

Esta unidade conforma um aquifero regional do tipo livre, localmente semi-confinado, com circulações de água numa velocidade de $0,04 \mathrm{~m} / \mathrm{dia}$ e transmissividades de 10 a $100 \mathrm{~m}^{2 / d i a}$ (DAEE, 1976, 1988). No que concerne à composição, são águas bi-carbonatadas cálcicas ou magnesianas e águas bicarbonatadas sódicas; secundariamente ocorrem águas cloro-sulfatadas cálcicas ou magnesianas e cloro-sulfatadas sódicas (Campos, 1987).

A Formação Serra Geral pertence ao Grupo São Bento e, compreende um conjunto de derrames de basaltos toleiticos entre os quais se intercalam arenitos com as mesmas caracteristicas dos pertencentes à Formação Botucatu. Sob o ponto de vista petrográfico, os basaltos apresentam composição mineralógica simples, constituidos essencialmente de labradorita zonada associada a clinopiroxênios (augita e às vezes pigeonita). Acessoriamente mostram-se titano-magnetita, apatita, quartzo e, raramente, olivina ou seus produtos de transformação (IPT, 1981).

O Aquífero Serra Geral é classificado como do tipo fraturado, livre, anisotrópico e heterogêneo. Localmente o intemperismo da rocha pode caracterizar um aquífero limitado do tipo po- roso. Os coeficientes de transmissividades existentes encontram-se entre 1 a $700 \mathrm{~m}^{2} /$ dia.

\section{FONTES DE POLUIÇÃO}

A presença de cromo nas águas subterrâneas está normalmente associada à contaminaçăo de origem antrópica. No norte dos Estados Unidos e em alguns locais do Japão, a contaminação das águas subterrâneas por este metal é preocupante. E melhor evidenciada em áreas onde estão instaladas indústrias de metal e de tratamento de madeira, curtumes, mineração de cromo e processos de beneficiamento do metal. Outras fontes de poluição podem ser citadas, como indústrias de manufaturas de pigmentos, de filmes fotográficos, de inibidores de corrosão, entre outras.

A ocorrência natural do elemento em concentrações acima das normas de potabilidade da água é bastante rara. As referências bibliográficas especializadas sobre 0 assunto são escassas. Robertson (1975) descreve o caso do Paradise Valley (Arizona, EUA), onde as concentraçốes de cromo variavam de 0,1 a 2,0 $\mathrm{mg} / \mathrm{l}$. Embora o autor não tenha estabelecido a origem primária do cromo, entende-se que este elemento está associado aos minerais de argila, cuja área-fonte não é reconhecida.

Szikszay (1981), no estudo das Fontes de Águas da Prata (SP), encontrou teores de cromo total variando de 0,014 a $0,3 \mathrm{mg} / \mathrm{l} \mathrm{em}$ águas provenientes de rochas vulcânicas e valores variando de 0,019 a $0,3 \mathrm{mg} / 1$, nas águas provenientes de arenitos.

Segundo Love (1967), poucas águas contêm cromo de fontes naturais. Aguas naturais podem contê-lo somente como elemento traço. Porém, na região de Urânia foram desenvolvidos estudos sobre a presença de cromo nas águas subterrâneas e constatou-se, que a ocorrência deste elemento é natural (Hirata 
\& Rodolfi, 1993; Hirata et al., 1994). Este resultado é baseado nas seguintes observaçōes: i) o cromo (VI) ocorre distribuido de forma ampla na região, o que discorda da contaminação antrópi$\mathrm{ca}$, onde o cromo aparece em áreas restritas, não ultrapassando algumas centenas de metros da fonte de origem; ii) sua maior concentração foi encontrada em poços tubulares de grande profundidade, o que reforça a origem natural, pois se houvesse uma aplicação de cromo em superficie, os poços cacimbas seriam os mais atingidos; iii) não havia nas proximidades dos poços atingidos nenhum indicio de atividade contaminante, mesmo no passado.

\section{METODOLOGIA}

O estudo sobre a ocorrência e distribuição espacial do cromo na região noroeste do Estado de São Paulo foi desenvolvido a partir das análises físicoquímicas das águas subterrâneas captadas pela Companhia Estadual de Saneamento Básico (SABESP), em diversas localidades, no período de 1977 a 1993. Os teores de cromo total foram plotados na Figura 2 para melhor visualização da extensão espacial da anomalia e na tentativa de estabelecer um padrão para a distribuição do cromo na região.

$O$ estudo de cromo hexavalente foi realizado através da amostragem de água subterrânea em 12 localidades do noroeste paulista. Este parâmetro foi analisado pelo método difenilcarbazida com o Espectrofotômetro MICRONAL, modelo B 380 . Os dados também foram plotados na Figura 2.

O estudo de cromo total em 6 poços de Urânia foi executado a partir dos resultados das análises físico-químicas das águas subterrâneas, realizadas pela SABESP, no período de 1977 a 1993.

Para o estudo de cromo total e hexavalente na cidade de Urânia e seu distrito Santa Salete, foram selecionados 4 poços. As águas destes poços apresentaram em análises anteriores, as maiores concentraçōes de cromo hexavalente $(0,08-0,10 \mathrm{mg} / 1)$. As amostras das águas subterrâneas foram coletadas diretamente dos poços que já estavam sendo bombeados a mais de uma hora, sem interrupção, em frascos de vidro, sendo que o cromo total foi preservado com $\mathrm{HNO}_{3}$ e $\mathrm{pH}<2$. Os métodos de análises químicas utilizados nos laboratórios da SABESP para cromo total foram o colorimétrico e para o cromo hexavalente o difenilcarbazida, sendo utilizados os equipamentos espectrofotômetro $\mathrm{HACH}$, modelo DR-2000 e Espectrofotômetro MICRONAL, modelo B 380 , respectivamente.

Através do cadastramento de poços foram selecionados os perfurados nos sedimentos da Formação Adamantina do Grupo Bauru e os que possuem entradas de água apenas nos basaltos da Formação Serra Geral. A partir deste estudo foi definido se as maiores concentrações de cromo total estavam em águas do Sistema Aquifero Bauru (sedimentos) ou do Sistema Aqüifero Serra Geral (basaltos).

Durante a perfuração de um poço em Urânia (poço 9), próximo ao Córrego Comprido, foram coletadas amostras de água em três profundidades diferentes $(114,180-182,270 \mathrm{~m})$ para análise de cromo total. Foram feitas também coletas de água para análise de cromo total em outros dois poços do município de Urânia, urn na Fazenda Jatobá e o outro no posto de gasolina Garção. Foram ainda analisados os teores de cromo total e hexavalente em duas amostras do córrego Comprido, para uma comparação das concentrações de cromo nas águas subterrâneas e superficiais.

Para estudar a ocorrência de cromo nos sedimentos, foram analisadas duas amostras que afloram em Urânia. Foram coletadas também três amostras de sedimentos do poço 9 durante a sua 


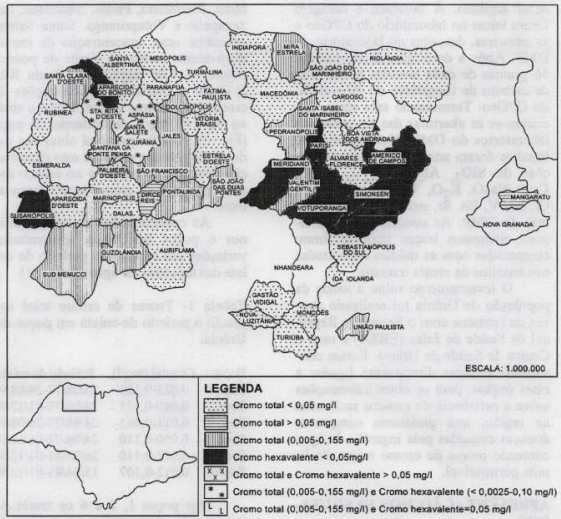

Figura 2 - Regiāo Noroeste do Estado de Sāo Paulo com as concentraçōes de cromo total e hexavalente nas águas subterrâneas. Fonte: Plano Cartográfico do Estado de Såo Paulo, Instituto Geográfico e Cartográfico, 1990.

perfuraçăo. Estas amostras foram secadas e moidas em um moinho de bolas de carbeto de tungstênio, no laboratório do Centro de Pesquisas Geocronológicas (CPGeo) do Instituto de Geociências da USP (IG/USP). A abertura das amostras foi feita nos laboratórios do Departamento de Mineralogia e Petrologia (DMP) do IG/USP. Foram analisados os elementos zinco, cromo, cobre, zircônio e ítrio por espectrometria de emissão atômica por plasma acoplado por indução (ICP-AES) do DMP. As concentra- çóes destes elementos nos sedimentos de Urânia foram comparadas com as médias encontradas em sedimentos equivalentes da crosta terrestre.

O estudo dos basaltos foi realizado através da análise de onze amostras de calha de rochas basálticas do poço 9 , de profundidades diferentes $(70,90$, $110,130,150,170,190,210,230,250$, $270 \mathrm{~m}$ ), de tal forma, que fossem representativas do perfil geológico do poço. Inicialmente os fragmentos das amostras foram lavados para remoção de ma- 
terial argiloso. A lavagem e secagem foram feitas no laboratório do CPGeo e as amostras, descritas no laboratório do DMP. Após a descrição, foram moídas 50 gramas de cada amostra no moinho de carbeto de tungstênio do laboratório do CPGeo. Terminando esta etapa, iniciaram-se as aberturas das amostras nos laboratórios do DMP. Nas amostras de basaltos foram analisadas as concentrações de $\mathrm{SiO}_{2}, \mathrm{Al}_{2} \mathrm{O}_{3}, \mathrm{Fe}_{2} \mathrm{O}_{3}, \mathrm{MgO}$, $\mathrm{CaO}, \mathrm{Na}_{2} \mathrm{O}, \mathrm{K}_{2} \mathrm{O}, \mathrm{TiO}_{2}, \mathrm{P}_{2} \mathrm{O}_{5}, \mathrm{MnO}$, $\mathrm{Cr}, \mathrm{Ni}, \mathrm{V}, \mathrm{Ba}, \mathrm{Sr}$, pelo ICP-AES (Plasma) do DMP. As concentraçōes de alguns elementos traços também foram comparadas com as médias encontradas nos basaltos da crosta terrestre.

O levantamento sobre a saúde da população de Urânia foi realizado através de contatos com o Escritório Regional de Saúde de Jales (ERSA) e com o Centro de Saúde de Urânia. Foram consultadas pessoas diretamente ligadas a estes órgãos, para se obter informações sobre a existência de estudos realizados na região, que pudessem comprovar doenças causadas pela ingestão de água contendo teores de cromo acima do limite permissivel.

\section{APRESENTAÇÃO DOS RESULTA- DOS}

Pela Figura 2 nota-se que o cromo total está distribuido por vários municípios e distritos do noroeste paulista. Em alguns locais suas concentrações sâo menores ou iguais ao limite de potabilidade $(\leq 0,05 \mathrm{mg} / 1)$. Em outros, estão acima deste limite $(>0,05 \mathrm{mg} / 1)$. Há ainda localidades em que as concentrações de cromo total nas águas subterrâneas variam abaixo e acima deste limite $(0,005-0,155 \mathrm{mg} / \mathrm{I})$.

As concentrações de cromo hexavalente na maioria das localidades estão abaixo ou no limite de potabilidade $(\leq$ $0,05 \mathrm{mg} / \mathrm{l}$ ), como Américo de Campos, Aparecida do Bonito, Aspásia, Cosmo- rama, Meridiano, Parisi, Simonsen, Suzanápolis e Votuporanga. Santa Salete, apresenta uma concentraçāo de cromo hexavalente acima do limite de potabilidade $(>0,05 \mathrm{mg} / \mathrm{l})$. Em Santa Rita D'Oeste e Urânia as concentraçôes de cromo hexavalente variam acima e abaixo de $0,05 \mathrm{mg} / \mathrm{l}$, dependendo do poço (Fig. 2). Não foi possivel obter um padrão que pudesse explicar esta distribuição irregular no tempo e no espaço das concentrações de cromo total e hexavalente.

As concentrações de cromo total nos 6 poços de Urânia apresentaram variações em relação ao período de coleta das amostras de água (Tabela 1).

Tabela 1- Teores de cromo total segundo o periodo de coleta em poços de Urânia.

$\begin{array}{lcc}\text { Poços } & \text { Cr total (mg/l) } & \text { Periodo de coleta } \\ \text { Poço 1 } & 0,023-0,122 & 24 / 08 / 77-20 / 08 / 90 \\ \text { Poço 2 } & 0,040-0,155 & 24 / 08 / 77-01 / 12 / 93 \\ \text { Poço 3 } & 0,011-0,043 & 24 / 08 / 77-20 / 08 / 90 \\ \text { Poço 4 } & 0,050-0,110 & 24 / 08 / 77-01 / 12 / 93 \\ \text { Poço 5 } & 0,052-0,110 & 26 / 05 / 81-01 / 12 / 93 \\ \text { Poço 6 } & 0,012-0,107 & 13 / 04 / 83-01 / 12 / 93\end{array}$

Nos poços 1, 2 e 6 os teores de cromo estiveram abaixo e acima do limite de potabilidade. No poço 4 os teores ficaram no limite de potabilidade e acima deste. No poço 5 , acima do limite. Apenas no poço 3 os teores deste elemento permaneceram abaixo do limite de potabilidade num período de 13 anos. Com isto, é possível observar que em relação ao tempo e a cada poço, as concentrações de cromo total apresentam um comportamento irregular.

Os teores de cromo total e cromo hexavalente $\mathrm{em}$ poços selecionados de Urânia e Santa Salete, em 3 coletas, num período de 83 dias, variaram de $0,08-0,13 \mathrm{mg} / 1$ e $0,07-0,10 \mathrm{mg} / 1$, respectivamente. A toxicidade do cromo e seus compostos depende de seu estado 
de oxidação, que pode ser +3 ou +6 . As formas trivalentes de cromo são nutricionalmente ativas, porém, o cromo hexavalente é tóxico e não apresenta valor nutricional. Os teores anômalos de cromo, apesar de não serem alarmantes, podem comprometer a qualidade das águas subterrâneas, sendo necessário um tratamento de redução deste elemento, que pode encarecer o custo da água potável.

Na maioria dos poços perfurados nos sedimentos, as concentrações de cromo total sāo menores do que 0,05 $\mathrm{mg} / \mathrm{l}$, variando de 0,005 a $0,040 \mathrm{mg} / \mathrm{l}$. Nos poços de São João das Duas Pontes e Urânia a concentração de cromo total encontra-se abaixo e acima de 0,05 $\mathrm{mg} /$, num intervalo de 0,011 a 0,155 $\mathrm{mg} /$. Nos poços com entradas de água apenas nos basaltos, as concentrações de cromo total encontram-se abaixo de $0,05 \mathrm{mg} / \mathrm{l}$, variando de 0,007 a 0,018 $\mathrm{mg} / \mathrm{l}$. Estes resuitados mostram que as maiores concentraçōes de cromo total são encontradas em águas provenientes dos sedimentos do Sistema Aqüífero Bauru.

O poço 9 foi perfurado no município de Urânia. Atravessa 67,60 metros de sedimentos da Formação Adamantina. A partir dessa profundidade e até 270 metros, encontram-se os basaltos da Formação Serra Geral. Toda a extensão de sedimento foi cimentada. A concentração de cromo total a 114 metros é de $0,03 \mathrm{mg} / 1$; a $180-182$ metros é de 0,01 $\mathrm{mg} / \mathrm{l}$; a 270 metros é $0,03 \mathrm{mg} / \mathrm{l}$. É importante ressaltar que nestas profundidades encontram-se os basaltos e que nos sedimentos superiores houve cimentação. Foram feitas coletas de água em dois poços no município de Urânia. Estes poços só atingem os sedimentos, e as concentrações de cromo total são mais altas do que as anteriores. No poço da Fazenda Jatobá, a concentração de cromo total é de $0,09 \mathrm{mg} / \mathrm{l}$. No poço do posto de gasolina Garçăo, a concentra- ção é de $0,05 \mathrm{mg} / \mathrm{l}$. Amostras coletadas no córrego Comprido apresentaram concentrações de cromo total e hexavalente abaixo do limite de deteç̧ão do equipamento $(<0,0025 \mathrm{mg} / \mathrm{l})$. Foram coletadas em locais diferentes, uma ao longo da extensão do córrego e a outra numa mina que deságua neste córrego. Estes resultados mostram que as concentraçôes de cromo em poços que só atingem os sedimentos são mais elevadas do que as do poço 9, que possui entradas de água apenas nos basaltos. As concentraçōes de cromo nas águas subterrâneas também são superiores às encontradas nas águas do córrego Comprido.

As amostras de sedimentos de Urânia são de ocorrência superficial, estando bem alteradas pelos fenômenos intempéricos. As de sedimentos do poço 9 também devem ser vistas com cuidado, uma vez que não são conhecidos os teores de cromo da lama de perfuração (bentonita) e não é possivel extraí-la das amostras de material argiloso. Nas rochas sedimentares a presença de cromo pode estar associada a minerais de argila. A montmorillonita, um tipo especifico de argila expansiva, comporta a substituiçâo atômica de um considerável número de elementos em sua estrutura, incluindo o cromo trivalente. Nestes minerais o cromo não tem origem primária. Foram analisadas cinco amostras de sedimentos, sendo que duas afloram em Urânia e três são do poço 9. As amostras que afloram em Urânia são as de código A 4 e A 6. A primeira é um solo argiloso amarronzado e foi coletada à margem do córrego Comprido, próxima ao poço 9. A segunda, apresentava-se menos alterada, com maior coesão e foi descrita como um argilito avermelhado, coletado próximo à lagoa de aeração, onde se localiza o poço 5 , que possui coordenadas geográficas $7761,50 / 538,20$. As amostras do poço 9 são as de código 18,30 , 54 , sendo que estes referem-se às pro- 
fundidades, em metros, em que foram coletadas. Estes sedimentos são argilosiltosos, na maioria das vezes avermelhados. Foram analisados os seguintes elementos: zinco $(\mathrm{Zn})$, cromo $(\mathrm{Cr})$, co- bre $(\mathrm{Cu})$, zircônio $(\mathrm{Zr})$ e ítrio $(\mathrm{Y})$. Suas concentraçōes são apresentadas na $\mathrm{Ta}$ bela 2 e comparadas com as concentraçōes médias destes elementos encontrados em folhelhos (Tabela 3 ).

Tabela 2 - Concentraçōes (ppm) de alguns elementos analisados nos sedimentos do poço 9 em Urânia.

Elementos

$\begin{array}{lcc}\text { analisados (ppm) } & \text { A 4 } & \text { A } 6 \\ \mathrm{Zn} & 87 & 123 \\ \mathrm{Cr} & 561 & 231 \\ \mathrm{Cu} & <20 & <20 \\ \mathrm{Zr} & 599 & 329 \\ \mathrm{Y} & <20 & 83\end{array}$

\section{Amostras}

$\begin{array}{cccc}\text { A } 6 \text { (rep.) } & 18 & 30 & 54 \\ 123 & 51 & 219 & 45 \\ 233 & 131 & 310 & 174 \\ <20 & <20 & <20 & <20 \\ 332 & 151 & 230 & 169 \\ 84 & <20 & <20 & <20\end{array}$

54

69

$<20$

A 6 (rep.): Repetibilidade.

$<2$

Tabela 3 - Concentração média de alguns elementos em folhelhos (ppm).

$\begin{array}{lcccccc}\text { Folhelho } & \mathrm{Zn} & \mathrm{Cr} & \mathrm{Cu} & \mathrm{Zr} & \mathrm{Sc} & \mathrm{Y} \\ \text { (ppm) } & 90 & 100 & 50 & 180 & 15 & 35 \\ \text { Fonte: Krauskopf (1979). } & & & & & \end{array}$

Comparando as Tabelas 2 e 3 nota-se que as concentrações de $\mathrm{Zn}$ dos sedimentos de Urânia, estão próximas às da média da crosta terrestre. As concentrações de $\mathrm{Cu}$ estão abaixo da média. No entanto, as concentrações de $\mathrm{Cr}$ e $\mathrm{Zr}$ dos sedimentos de Urânia nem sempre coincidem com as médias da crosta terrestre, sendo que o cromo nos sedimentos de Urânia está acima da média em todas as amostras. As concentrações de Cr e $\mathrm{Zr}$ na amostra A 4 estão muito acima da média encontrada na crosta terrestre. O ICP-AES possui um limite de detecção dos elementos, de 20 ppm, para o tipo de abertura de amostra que foi seguido. Por isso, as concentrações com o sinal $<20$ ppm não possuem um valor absoluto. Com a amostra A 6 foi feito um teste de repetibilidade. Os resultados de A 6 e A 6 (rep.) são semelhantes, mostrando que existe uma boa repetição dos resultados.

As onze amostras de basaltos do poço 9 foram descritas utilizando-se um estereomicroscópio do DMP. A maioria delas é melanocrática de textura faneritica fina e não apresenta vesiculas. Algumas amostras contêm calcita, que foi extraída por catação por pinça. Nos basaltos determinou-se as concentrações dos seguintes elementos: $\mathrm{SiO}_{2}, \mathrm{Al}_{2} \mathrm{O}_{3}$, $\mathrm{Fe}_{2} \mathrm{O}_{3}, \mathrm{MgO}, \mathrm{CaO}, \mathrm{Na}_{2} \mathrm{O}, \mathrm{K}_{2} \mathrm{O}, \mathrm{TiO}_{2}$, $\mathrm{P}_{2} \mathrm{O}_{5}, \mathrm{MnO}, \mathrm{Cr}, \mathrm{Ni}, \mathrm{V}, \mathrm{Ba}, \mathrm{Sr}$ (Tabela 4).

$\mathrm{Na}$ Tabela 5 são apresentadas as concentrações médias de alguns elementos encontrados nos basaltos.

Nas rochas igneas, o cromo está presente em piroxênios, um mineral silicático. Estes minerais têm uma composição altamente variável devido à substituição atômica. $\mathrm{O}$ elemento em questão pode ocorrer em até $1,2 \%$ em alguns diopsídios $\left[\mathrm{CaMg}\left(\mathrm{Si}_{2} \mathrm{O}_{6}\right)\right]$ e em algumas augitas $\left[(\mathrm{Ca}, \mathrm{Na})\left(\mathrm{Mg}, \mathrm{Fe}_{2}, \mathrm{Fe}_{3}, \mathrm{Al}\right)\right.$ $(\mathrm{Si}, \mathrm{Al})_{2} \mathrm{O}_{6}$ ] (Mason, 1971). Ruegg (1975) reconhece a presença de cromo 
Tabela 4 - Concentrações (ppm) de alguns elementos analisados nos basaltos do poço 9 em Urânia.

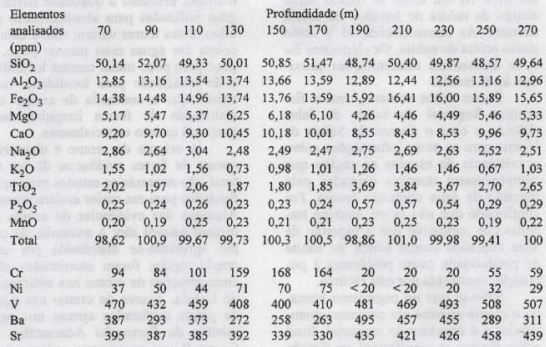

Tabela 5 - Concentração média de alguns elementos em basaltos (ppm).

$\begin{array}{ccccccc}\text { Basalto } & \mathrm{Cr} & \mathrm{Ni} & \mathrm{Co} & \mathrm{V} & \mathrm{Ba} & \mathrm{Sr} \\ \text { (ppm) } & 200 & 150 & 48 & 250 & 300 & 450\end{array}$

Fonte: Krauskopf (1979).

nas rochas basálticas como elemento traço, em concentraçōes que atingem até $240 \mathrm{ppm}$, com $25 \%$ das amostras com concentrações variando de 140 a 160 ppm. Pela Tabela 4 é possível constatar que os basaltos podem ser divididos em quatro grupos com características geoquímicas diferentes, de acordo com a profundidade. Estes grupos apresentam concentrações equivalentes para cada elemento. O grupo I corresponde às profundidades 70,90 e 110 metros. $O$ grupo II, 130,150 e 170 metros. O grupo III, 190,210 e 230 metros, e o grupo IV, 250 e 270 metros. Os topos dos derrames, identificados pelo caráter alterado e amigdaloidal dos basaltos, encontram-se nos seguintes intervalos de profundidade: 110-124 metros, 178180 metros, 240-246 metros. Os basaltos da Bacia do Paraná podem ser classificados em três grupos, de acordo com a porcentagem de $\mathrm{P}_{2} \mathrm{O}_{5}$ e TiO $\mathrm{Ti}_{2}$ (Piccirillo, 1988): $\mathrm{HPT}$ (high $\mathrm{P}_{2} \mathrm{O}_{5}$ e $\mathrm{TiO}_{2}$ ) > $3 \% \mathrm{TiO}_{2}$; LPT (low $\mathrm{P}_{2} \mathrm{O}_{5}$ e TiO $\left.\mathrm{TiO}_{2}\right)<2 \%$ $\mathrm{TiO}_{2} ;$ IPT (intermediate $\mathrm{P}_{2} \mathrm{O}_{5}$ e $\mathrm{TiO}_{2}$ ) $2-3 \% \mathrm{TiO}_{2}$. Nos basaltos do poço 9 de Urânia podem ser claramente identificados representantes de todos estes três grupos. O grupo II é classificado como LPT e apresenta baixas concentraçóes de $\mathrm{Ti}$ e $\mathrm{P}$ e altas de $\mathrm{Mg}, \mathrm{Ca}, \mathrm{Cr}$ e Ni. O grupo III corresponde ao HPT, com altas concentraçōes de $\mathrm{Fe}, \mathrm{Ti}, \mathrm{P}, \mathrm{Ba}, \mathrm{Sr}$. Os HPT são considerados predominantes no Estado de São Paulo. 
Comparando as Tabelas 4 e 5 , nota-se que as concentrações dos elementos $\mathrm{Cr}$ e $\mathrm{Ni}$ em todas as rochas estão abaixo da média de basaltos da crosta terrestre. As concentraç̃es de V estão muito acima da média. Os elementos $\mathrm{Ba}$ e Sr apresentam concentrações próximas às da média.

Foram feitos contatos com o Escritório Regional de Saúde de Jales (ERSA) e com o Centro de Saúde de Urânia para se obter informações sobre a existência de estudos na região que comprovassem doenças causadas pela ingestão de água contendo cromo. Foi confirmado que não existe nenhum trabalho que comprove que a ingestâo de água contendo cromo acima do limite de potabilidade cause problemas à população abastecida por este recurso.

Sabe-se que no organismo humano o cromo aparece em pequenas quantidades e é considerado essencial. Suas ações tóxicas se manifestam em função da dosagem, forma química e estado nutricional do organismo exposto. Desta forma, para garantir efeitos benéficos ao organismo, é preciso que suas concentrações estejam dentro dos limites permitidos. O excesso ou a falta dos elementos traços podem induzir alteraçōes bioquímicas que afetam as funções fisiológicas, provocando efeitos que variam em intensidade de acordo com a idade, sexo e espécie do organismo em estudo (Amaral, 1985).

\section{CONCLUSŌES}

A anomalia de cromo estende-se, além da cidade de Urânia, a outros municípios e distritos do noroeste paulista, não significando que em locais onde não foram feitas análises químicas das águas subterrâneas, ela não esteja presente.

Os teores de cromo nas águas subterrâneas de diversas localidades do noroeste paulista são variáveis, sendo que em alguns locais ultrapassam os limites máximos permissíveis para o consumo humano, afetando a qualidade destas águas utilizadas para abastecimento público. Estes teores variam com a data de coleta das águas num mesmo poço, de poço para poço numa mesma localidade e de localidade para localidade, mostrando que a anomalia de cromo está distribuída de forma irregular, tanto temporal quanto espacialmente.

A origem do cromo é discutivel, apesar de fortes evidências de ser natural, são necessários estudos mais aprofundados para um maior esclarecimento. Algumas das evidências do cromo ter origem natural são: a anomalia de cromo apresenta-se distribuida por uma ampla região; foram encontradas altas concentrações de cromo nos sedimentos de Urânia. Teores de cromo nas águas de poços perfurados apenas nos sedimentos da Formação Adamantina do Grupo Bauru apresentam valores mais altos do que nas águas de poços com entradas de água apenas nos basaltos da Formação Serra Geral. Estes dados evidenciam que, se a origem é natural, pode estar associada aos sedimentos da Formação Adamantina.

Não existem conclusões evidentes se os teores de cromo acima do limite de potabilidade podem causar problemas à saúde da população abastecida por estas águas.

\section{REFERÊNCIAS BIBLIOGRÁFICAS}

ALMODOVAR, M.L.N. (1995) Estudo da anomalia de cromo nas águas subterrâneas da região noroeste do Estado de São Paulo. São Paulo. 101p. (Dissertação de Mestrado) Instituto de Geociências, Universidade de São Paulo.

AMARAL, R. (1985) Importância dos elementos essenciais em águas para consumo humano. In: CONGRESSO BRASILEIRO DE ENGENHARIA 
SANITÁRIA E AMBIENTAL, 13 ., Maceió, 1985. Anais. São Paulo, CETESB/ABES. $14 p$.

BRANDT NETO, M. (1977) Estratigrafia da Formação Bauru na Regiâo do Baixo Tietê. São Paulo, 74p. (Dissertação de Mestrado) Instituto de Geociências, Universidade de São Paulo.

BRANDT NETO, M. (1984) O Grupo Bauru na Região Centro-Norte do Estado de São Paulo. São Paulo, 2v. (Tese de Doutorado) Instituto de Geociências, Universidade de São Paulo.

BRANDT NETO, M.; PETRI, S.; COIMBRA, A.M. (1985) Argilominerais do Grupo Bauru: considerações genéticas. In: SIMPÓSIO REGIONAL DE GEOLOGIA, 5., São Paulo, 1985. Atas. São Paulo, SBGNúcleo de São Paulo. v.1, p.61-74.

BRASIL. COMPANHIA DE TECNOLOGIA DE SANEAMENTO AMBIENTAL (1994) Compilação de Padrōes Ambientais. São Paulo, CETESB. 7p.

BRASIL. DEPARTAMENTO DE AGUAS E ENERGLA ELÉTRICA (1976) Estudo de Águas Subterrâneas: Regiôes Administrativas 7,8 e 9. São Paulo, DAEE. 4v.

BRASIL. DEPARTAMENTO DE ÁGUAS E ENERGLA ELÉTRICA (1988) Água subterrânea reserva estratégica. Águas e Energia Elétrica, v.5, n.13, p.14-23.

CAMPOS, H.C.N.S. (1987) Contribuição do estudo hidrogeoquímico do Grupo Bauru no Estado de São Paulo. São Paulo, 158p. (Dissertação de Mestrado) Instituto de Geociências, Universidade de São Paulo.

COIMBRA, A.M. (1976) Arenitos da Formação Bauru: estudo de áreasfonte. São Paulo, 2v. (Dissertação de Mestrado) Instituto de Geociências, Universidade de São Paulo.

HIRATA, R.; RODOLFFI, G. (1993)
Presença de cromo nas águas subterrâneas em Urânia. São Paulo, Secretaria do Meio Ambiente/Instituto Geológico. 24p. (Relatório Técnico).

HIRATA, R.; RODOLFFI, G.; ALMODOVAR, M.L.N. (1994) O cromo nas águas subterrâneas do noroeste paulista: origem e linhas para uma pesquisa de detalhe: In: CONGRESSO BRASILIRO DE GEOLOGLA, 38., Camboriú, 1994. Boletim de resumos expandidos. Camboriú, SBG, v. 3, p. 333-334.

INSTITUTO GEOGRÁFICO E CARTOGRÁFICO DO ESTADO DE SÃO PAULO (1990) Plano cartográfico do Estado de São Paulo. São Paulo, IGC. Escala 1:1.000.000.

INSTITUTO DE PESQUISAS TEC. NOLÓGICAS (1981) Mapa geológico do Estado de Sâo Paulo. São Paulo, IPT. v.1. Escala 1:500.000.

KRAUSKOPF, K.B. (1979) Introduction to geochemistry. 2.ed. Tokyo, McGraw-Hill Kogakusha. p.544-546.

LOVE, S.K. (1967) Quality of surface waters of the United States 1963. Parts 1 and 2. North Atlantic Slope and South Atlantic Slope and Eastern Gulf of México Basins. U.S.Geological Survey Water Supply Paper. p. 15 .

MÁSON, B.H. (1971) Princípios de Geoquímica. Săo Paulo, EDUSP. 403p.

PICCIRILLO, E.M.; MELFI, A.J. (1988) The mesozoic flood volcanism of the Paraná Basin: petrogenetic and geophysical aspects. São Paulo, Universidade de São Paulo/ LAG. 600 p.

ROBERTSON, F.N. (1975) Hexavalent Chromium in the ground water in Paradise Valley, Arizona. Ground Water, v.13, n.6, p. 516-527.

RUEGG, N.R. (1975) Modelos de variação química na província basálticas do Brasil Meridional: ca- 
racteristicas de teor, distribuiçâo geográfica e diferenciação. São Paulo, v.1 (Tese de Livre-Docência) Instituto de Geociências, Universidade de São Paulo.

SOARES, P.C.; LANDIM, P.M.B.; FÚLFARO, V.J.; SOBREIRO NETO, A.F. (1980) Ensaios de caracterização estratigráfica do Cretácio no Estado de São Paulo: Grupo Bauru. Revista Brasileira de Geociências, v.10, n.3, p.177-185.

SZIKSZAY, M. (1981) Hidrogeologia das Fontes de Águas da Prata, Estado de São Paulo. São Paulo, 2v. (Tese de Livre-Docência) Instituto de Geociências, Universidade de Săo Paulo.

M.L.N.Almodovar - Instituto de Geociências, Universidade de São Paulo, Caixa Postal 11.348, CEP 05422-970, São Paulo, SP. 